\title{
Community Participation in the Preparation and Implementation of Land Use Plans in Ghana: A Critical Assessment from the Tamale Metropolis
}

\author{
Paul Kitson Baffour Asamoah ${ }^{1 *}$ Takora Saaka $^{2} \quad$ Nicholas Kombonaah $^{3} \quad$ Eric Appiah Atiemo ${ }^{4}$ \\ 1.Centre for Settlements Studies, College of Art and Built Environment, Kwame Nkrumah University of Science \\ and Technology, Kumasi-Ghana \\ 2.Metropolitan Director of Planning,Tamale Metropolitan Assembly,Tamale-Ghana \\ 3.Nicholas Kombonaah, Department of Urban Roads, Wa Municipal Road Unit, P. O. Box 16, Wa, Ghana \\ 4.Eric Appiah-Atiemo, Centre for Settlements Studies, College of Art and Built Environment, Kwame Nkrumah \\ University of Science and Technology,Kumasi-Ghana
}

\begin{abstract}
Preparation of land use plans to address development challenges of urban centres globally stand the chance of becoming a success if the intended beneficiaries are actively involved in the process from the onset. This study was undertaken primarily to investigate the involvement of residents in Tamale in the preparation of land use plans in the metropolis. The specific objectives were to: examine how residents in the metropolis are engaged in the preparation of land use plans; find out the awareness of residents in the decentralised land use planning system; assess the level of involvement of the community in the preparation of land use plans; examine the benefits that the community stands to gain through their involvement; and to analyse the challenges of community participation in land use plan preparation in the Metropolis. The study employed the case study as its research design and the mixed method, i. e. emphasising both qualitative and quantitative approaches. About 110 households were scientifically selected using simple random sampling technique. The sample size was determined by the formula $\frac{N}{1+N(e)^{2}}=n$. In addition, 11 stakeholder intuitions in the metropolis were also contacted. The study found that residents are involved in the preparation of land use plans through consultation (just by information). In addition, the investigation found that awareness of the decentralised planning system was very low (27.3 percent), which invariably affected their participation in the preparation of land use plans (28.1 percent). The study again found that people agreed that factors such as leadership qualities, resources and centralisation of decisions have great influence on successful community participation. The benefits of engaging communities in plan preparation included, sustainability of the plan, ownership of the by the community during implementation. Challenges face in the process of involving the community in the preparation of land use plans in the metropolis included slowdown in the process of decision making and lack of attention for spatial planning by government. The study concluded by advocating for strong sensitisation of residents on the decentralised planning system which is the new regulatory machinery for spatial planning activities in the Metropolis and Ghana as a whole.
\end{abstract}

Keywords: Land use, plans, planning system, participation, stakeholders.

DOI: $10.7176 /$ PPAR/9-9-05

Publication date:September $30^{\text {th }} 2019$

\section{Introduction}

Over the years there had been paradigm shift from planning for the people to planning with the people and therefore in terms of land use plan preparation the axiom is that the residents must be involved. This paradigm shift contributed to the enactment of a new planning regulation, which recognises the active involvement of citizens among others in the preparation of land use plans in the country. The concept of participation in development activities is certainly not a new one. One of the cornerstones of democracy is the participatory decision-making process which is required by those in government. Public participation in governance and development projects involves the direct involvement or indirect involvement through representatives of concerned stakeholders in decision making about policies, plans or programs in which they have interest. Through public participation, stakeholders may interact with government agencies, political leaders, non-profit organizations and business organizations that create or implement public policies and programs (Smith, 2010). Community involvement ranges from participation in activities defined by outsiders to the management and ownership of activities developed primarily by community members themselves (Aubel \& Samba 2006). The decentralisation concept in Ghana was initiated to promote popular grassroots participation in the administration of the planning, implementation, monitoring and delivery of services to improve the living conditions of the rural poor (Ahenkan, Bawole \& Domfeh, 2013). According to Local Government Act, 1993, Act 462, now the Local Governance Act, 2016, Act 936, the new decentralised development planning system in Ghana made Districts the main focus of planning action through a participatory approach. This process provides greater opportunity for 
the local communities within the districts to participate effectively in the conception, planning and implementation of development programmes and projects. The purpose of community participation in the preparation of land use plans is to influence decisions and proposals that affect the lives of citizens. According to Babette (2011), integrated participatory planning generally aims to introduce or improve a complete spatial planning approach at local level. Eco-Trust-Canada (2009), affirmed that participatory land use planning has led many communities to realize unexpected benefits beyond their initial planning intentions. It is therefore against this that the study was conducted to assess the involvement of resident of Tamale in the land use planning process in the Metropolis based on the knowledge in the land use plan preparation.

\subsection{Significance of study}

As villages grow to become urban centres and urban centres metamorphous into metropolitan areas, the supply of land becomes scarce. There is the need for judicious use of land through effective and all-embracing good land use plans to facilitate a balance between the various uses. This can only be done when land use plans are prepared to cover the needs and aspirations of the beneficiaries in the urban centres. Community participation in the process of preparing land use plans is paramount because regional developers believe that for plans to succeed, communities need to actively partake in designing, implementing and sustaining the plans that affect their conditions of living and day-to-day activities. The findings of the study are expected to be useful for national development, as it will attempt to investigate and find answers to the underlying factors inhibiting community participation in land use plan preparation and implementation and further serve as input into government guidelines for sustainable and effective land use planning in the country. In addition, the study is to serve as an important source of literature for both theoretical and applied researches in community participation in land use plan preparation and implementation in fast growing communities. The study also identified possibly areas for future research.

\section{Literature Review}

Many studies have been carried out in this area and researchers agree that community participation is key to the acceptance of projects bordering on implementation of land use plans and community ownership of plans. Literature review basically looks concepts underpinning community participation and the conceptual framework guiding the study

\subsection{The Concept of Community}

The definitions for community vary but convey the same meaning. According to Fortmann \& Roe (2013), communities are typically, not universally, defined on the basis of their geographical foundations, as occupying a particular geographical space. UNDP (2005), also defined community as a group of people living in a geographically defined area, or a group that interacts because of common social, economic, or political interests. The existence of community is not something that can be demonstrated, it is a philosophical point of departure that is shared, albeit implicitly by most of the key players (Schouten \& Moriarty, 2003). Shaeffer (2008) explained that communities are either homogeneous or heterogeneous group of people who may be either united or be conflictive and are governed and managed by leaders chosen democratically who act relatively autonomously from other levels of government. However, communities can be defined by characteristics that the members share, such as culture, language, tradition, law, geography, class, and race.

\subsection{Participation}

The World Bank (2014) defines participation as a process through which stakeholders' influence and share control over development initiatives, decisions and resources. This means that gone are those times when development agents had to solely determine, design and impose development projects or plans on intended beneficiaries. This has precipitated grassroots movements demanding participation in project planning and decision making (Bastian \& Bastian, 2006). Kasiaka (2004) stated that, 'participation is an approach through which beneficiaries and other stakeholders are able to influence project planning, decision-making, implementation and monitoring phases.

\subsection{Stakeholders}

Public participation in governance and development projects involves the direct or indirect involvement (through representatives) of concerned stakeholders in decision-making about policies, plans or programs in which they have an interest. Stakeholders are persons, groups or organizations that may influence or be affected by policy decisions (Freeman, 2010). They may interact with government agencies, political leaders, non-profit organizations and business organizations that create or implement public policies and programs (Smith, 2010). In the explanation of Thenen R. (2007), all stakeholders should be able to actively or somewhat participate in the design of a project to make sure that all interests are taken into consideration. 
However, in recent times participation is associated with some difficulty, which Fetterman (2005) explained that, while participation is about engaging people, it sometimes deprives groups, because it puts much emphasis on beneficiaries to the detriment of other significant stakeholders such as donors, Government and NGOs who command the greater proportion of resource and technical skills. This according to Woodhill (2004), explained that, most communities are limited in terms of resources and require skills to provide as well as manage facilities effectively and efficiently. Also, according to Kumur (2002), participation places empowerment of the beneficiaries at the center where the people or communities have to be empowered to make decisions where donors, governments, and other players may have to relinquish power and control. Goddard \& Cotter (1987); cited in Woodhill (2004) argue that participation is a development strategy that has been oversold. Implying, the theory is not without some shortcomings and so must be adopted with a bit of caution. Notwithstanding the above criticism, participation as a development model can serve as a significant basis towards community participation in preparation of land use plans. The term participation as explained can then lay the fundamental principle for community participation in land use plans preparation dialogue, and a key concept in land use plans discourse (Simpungwe, 2006).

\subsection{Community Participation}

The term community participation carries the interpretations and inclinations that cannot be divorced from the broader aim of encouraging the active participation of local people in the process as a whole (Oakely, 2009). Community involvement ranges from participation in activities defined by outsiders to the management and ownership of activities developed primarily by community members themselves (Aubel \& Samba 2006). The foundation of community-based development initiatives is the active involvement of members of a defined community in at least some aspects of project design and implementation (Mansuri \& Rao, 2004). Theoretically, a model developed to establish community participation is the one developed by Ainstein (1969). This theory of community participation is also called "a ladder of citizen participation", was used to evaluate participation according to Arnstein's understanding and experiences in urban areas of the United States in the 1960s. The ladder of participation as developed by Ainstein is shown in figure 1.

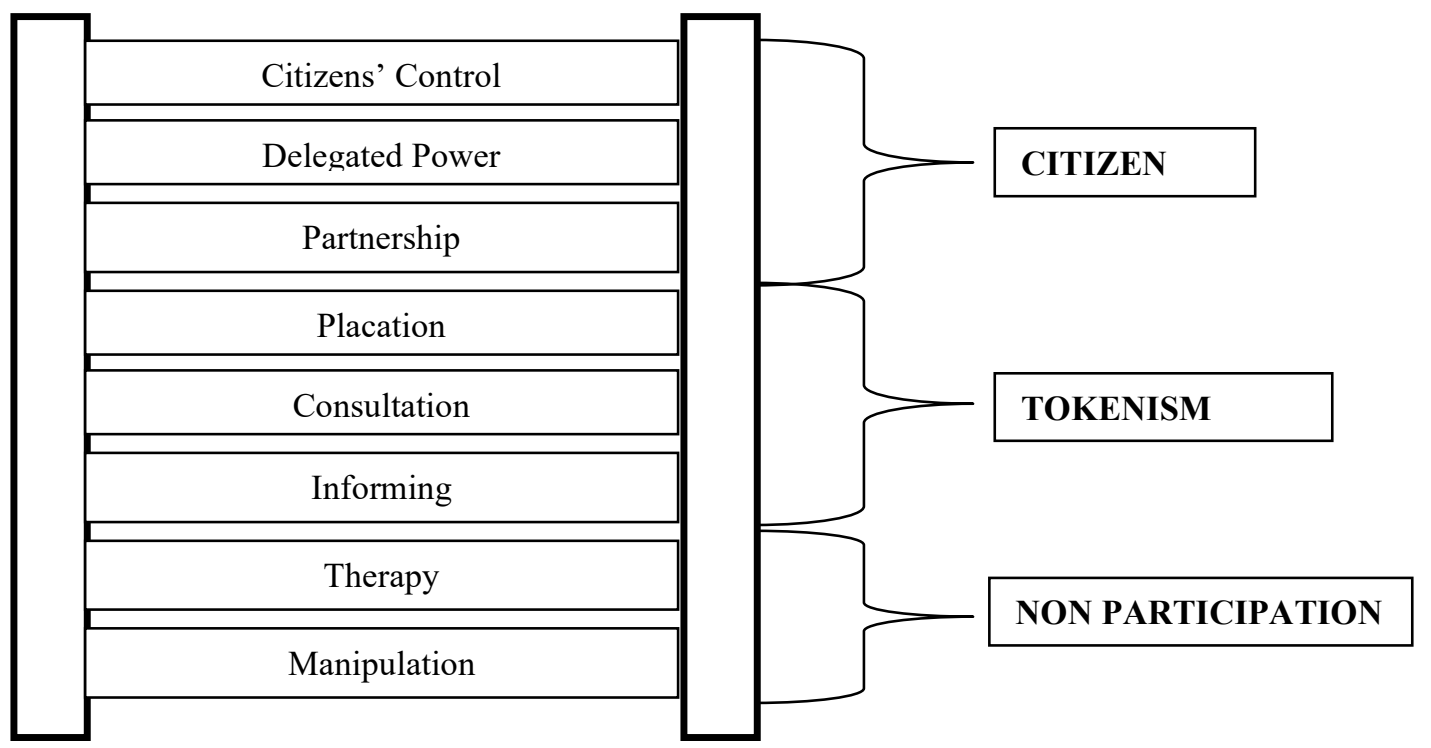

Figure 1: The Eight Rungs on the Ladder of Participation

Source: Ainstein, (1969)

The lowest rungs of the ladder are Manipulation and Therapy, which describe the levels of nonparticipation. Arnstein continues that rungs three and four, i.e., Informing and Consultation, enhance participation to levels of Tokenism and allow people to hear and to have a voice. The higher rungs of the ladder signify that citizen power, particularly decision-making power, has dramatically increased. In the Partnership stage, people are enabled to debate and involve themselves in negotiations with power-holders. On the highest rungs of Delegated Power and Citizen Control, citizens achieve the majority of decision-making seats or attain full managerial power. Thus, it is clear that this model for evaluating participation fits the theory of participatory democracy.

\subsection{Conceptual Framework}

Community participation is not a new concept and Ghana has policies and regulations that empower the local people to participate in the decision making process. As stated by Wasilwa, (2015), participatory land use 
planning is people centered, bottom- up approach that recognizes the differences that exist from place to place with respect to socio-economic, technological and environmental conditions.

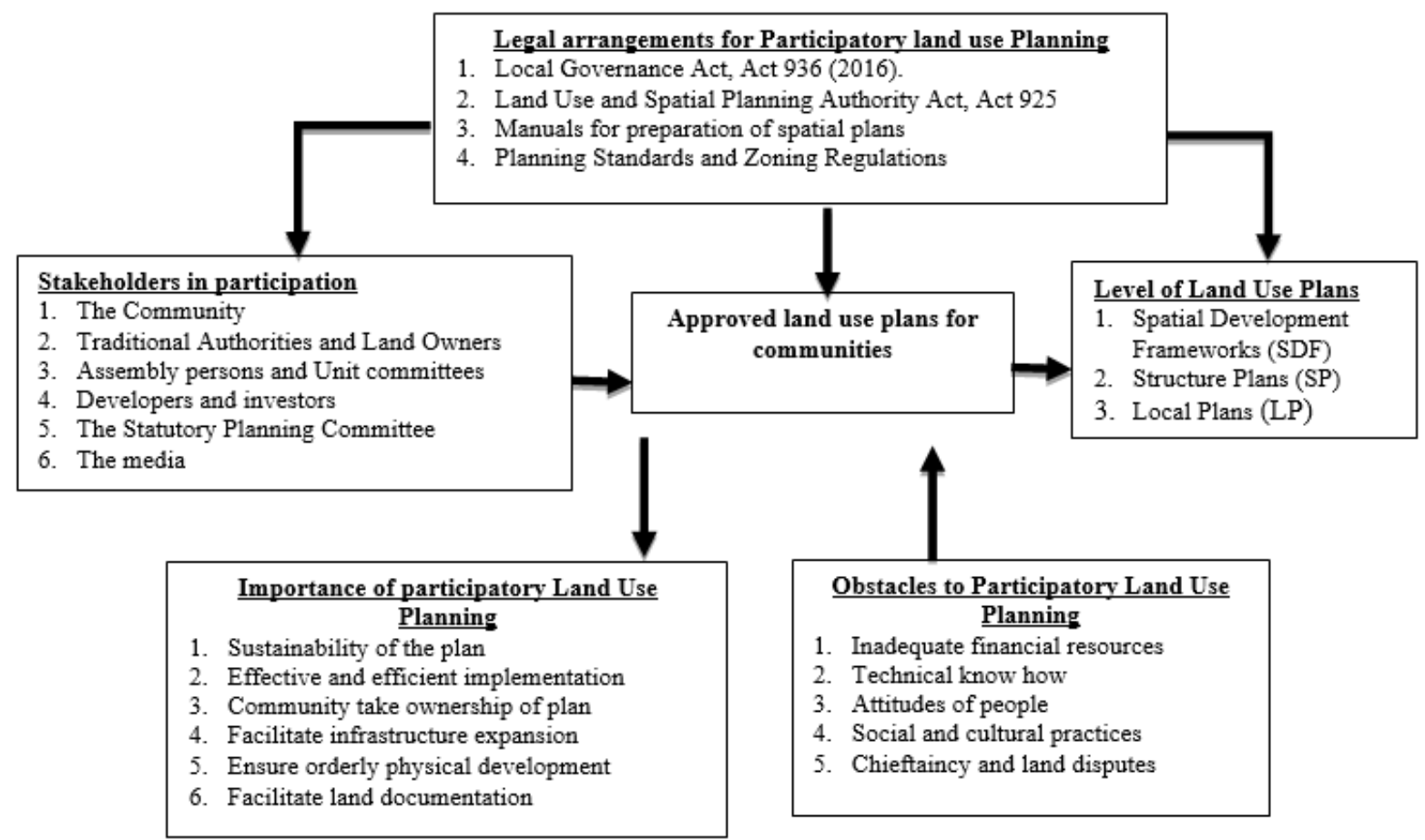

Figure 2: Community Participation in Preparation of Land Use Plans

Source: Adopted from Wasilwa, (2015)

Figure 2 was developed to give an appreciation of the framework for the participation in the preparation of land use plans, the regulations involved, the obstacles to participation and the importance of community participation in the land use planning process. The figure indicates that, to complete an effective land use plan, various stakeholders need to be involved in the process as well as the utilization of planning regulations, policies, planning manuals and zoning guidelines. Also it has been noted that a well-planned and implemented community plans has a lot of benefits. This notwithstanding, there are a number of obstacles that hinder stakeholders' participation of approved land use plans. The processes involve results in stagnation in the final approval of the plans and this should be noted when considering participatory land use planning.

\section{Methodology and Study Area Profile}

The Tamale Metropolitan Assembly (TaMA) is one of the four Metropolitan assemblies in Ghana and is located at the centre of the Northern Region (see Plate 1). It shares boundaries with Sagnarigu Municipality to the north, Tolon and Kumbungu Districts to the north-west, Central Gonja District to the South-West, East Ganja to the South and the Yendi Municipal Assembly to the east (see Plate 2). The Tamale Metropolis occupies approximately 750 square kilometres which constitutes 1.07 percent of the total land area of the Northern Region. 


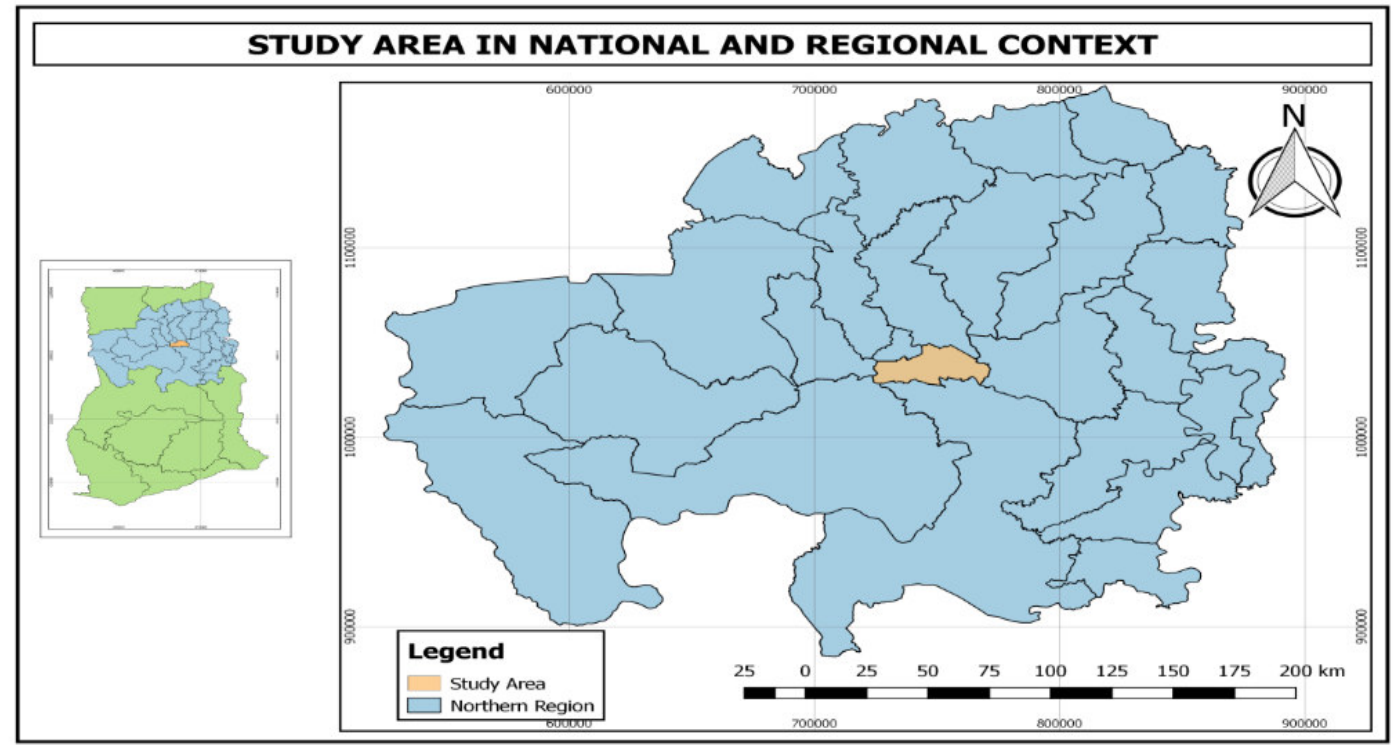

Plate 1: Map of Tamale Metropolis in Regional and National Context

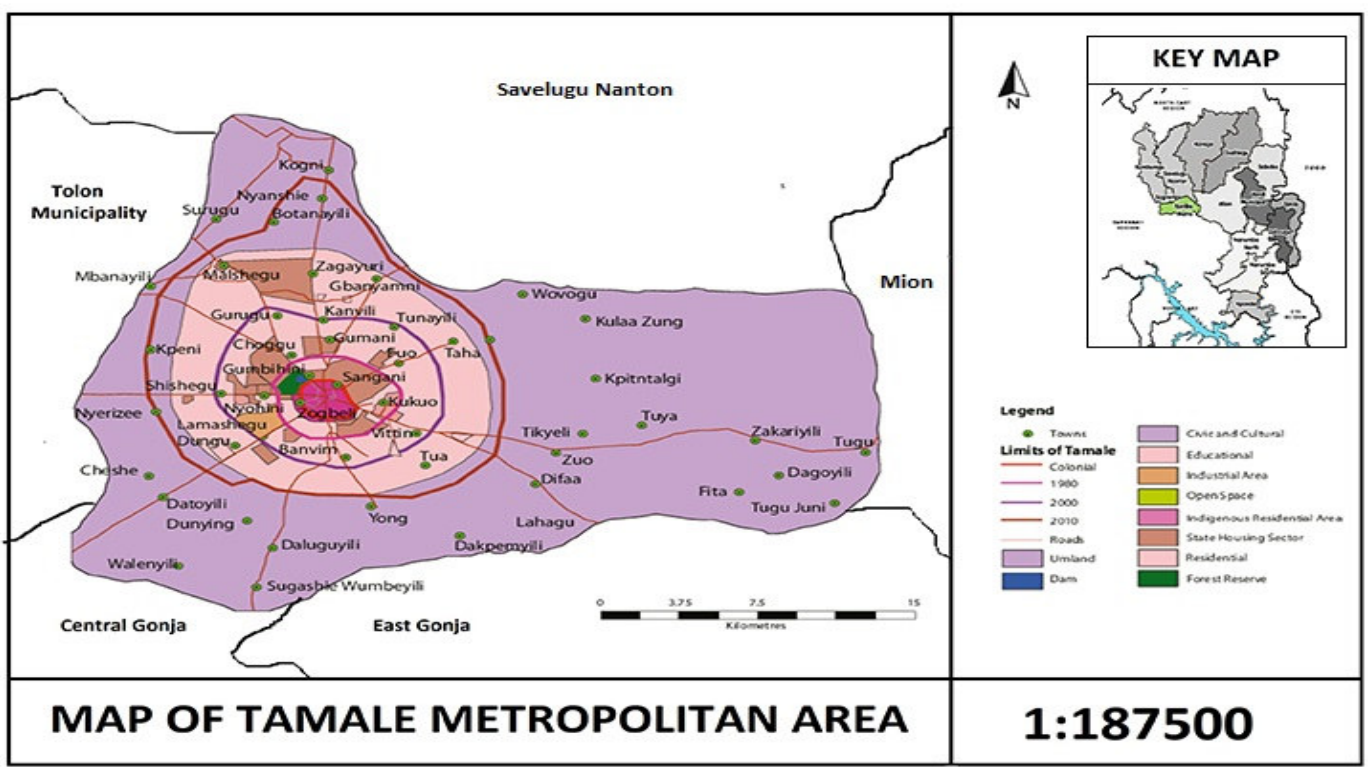

Plate 2: Map of Tamale Metropolis in Regional Context Showing the Communities

Source: Gyasi et al. (2014), uploaded by Adelina Maria Mensah.

Considering the nature of issues on community participation in the preparation of local plans in Ghana, the study was encapsulated in the case study research design. The mixed method approached to research was adopted emphasising both quantitative and qualitative approaches. The target population sampled for the study was the households (35,983 households). With margin of error of 5 percent, the sample size for the study was 110 households using the formula; $\frac{N}{1+N\{6\}^{2}}$. The population was first stratified and simple random sampling technique was used to select the respondents. The reason was to give equal opportunity to all members of the population of being selected. In addition, institutions in the metropolis which are key stakeholders in the preparation of land use plans were purposely selected and contacted during the data collection stage of the study. There were face to face interviews using structured questionnaire to solicit for household data, whilst interview guide was use for data collection from institutions and key informants within the metropolis.

\section{Analysis and Discussion}

\subsection{Age and Sex Distribution of Respondents}

Issue of gender in the study was to assess the involvement of both men and women in the development planning process in the Tamale Metropolis. Majority of the respondents were within the ages of 45-54 (43.6 percent) 
while only 6.4 percent of them were within the ages of 18-24 years. In addition, most of the respondents were males indicating male dominance in decision making with regards to land use planning

\subsection{Community Participation in Decentralised Planning and Land Use Planning}

Creating awareness is a form of community participation in the development planning process. Awareness of the decentralised planning system of the people in the metropolis is an indication that the Metropolitan Assembly is gradually adopting the bottom-up approach to development. Premised on this, the study revealed that 27.3 percent of respondents are aware of the concept of the decentralised planning system while 72.7 percent have no idea at all of the process. Even though 27.3 percent admitted they are aware of the system, only 15.6 percent could explain the processes involved in the decentralised planning system while the rest agree they only heard about the system during meetings. This situation implies that a lot of the local people are not properly informed about the system and its components which can affect participation in the preparation of land use plans in the metropolis.

The study indicated that 28.2 percent of the respondents agreed that community members are involved in the preparation of land use plans as against 71.8 percent who said communities do not participate in the planning process at all. Even though 28.2 percent admitted that community members are involved in the plan preparation, all of them said they have never participated in the preparation of any land use plan in the metropolis. This therefore means that the communities do not know, or are apathetic towards decision making. It also implies that completed and approved land use plans might not address the needs, concerns and aspirations of communities affected by the plan as well as its implementation.

\subsection{Organization of Communities in the Land Use Planning Process}

This is to show the mode and/or the level of involvement of communities in the land use planning process in the metropolis. It was revealed that the main mode of engagement of communities is through stakeholders' consultative meetings with total score of 49.1 percent. This view was further confirmed by the Town and country Planning Department that, since it is always difficult to organize the entire community, during the plan preparation process, key stakeholders such as chiefs/land owners, assembly persons, land sector agencies, civil society groups among others are usually engaged on behalf of the general citizenry. According to the Ainstein's ladder of participation, this falls within tokenism under placation. At this level, "a few hand-picked "worthy" poor on boards of Community Action Agencies or on public bodies like the board of education, police commission, or housing authority. If they are not accountable to a constituency in the community and if the traditional power and other community heads and authorities (powerholders) assume the place on behalf of the citizenry" (Ainstein, 1969).

This means that due diligence needs to be done in the process of stakeholders' selection to ensure that diverse groups are properly represented to provide inputs that address the aspirations of the community. The study further revealed that the key stakeholders' consultation meetings is done once at the draft stage of the plan, which they cannot even tell whether their inputs are incorporated into the final plan. The other forms of involvement include community workshop sessions (17.3 percent), both meeting and workshops (18 percent). Town and Country Planning Department explained that the "normal process in involving communities in the plan preparation should start from data collection and analysis, formulation of goals and objectives, generation of development scenarios, selection of the best option, implementation of the approved plan and the monitoring of proposals. But due to inadequate resources, the process is not religiously followed because financing of planning schemes is left in the hands of the chiefs and land owners" (Field Survey, Tamale Municipal, 2018). This in a way limits participation in the real sense of the word.

About 90.9 percent of the respondents admitted that for any given plan preparation, a community will only meet once while 9.1 percent attested that they meet twice. The fact that meetings are organised once means that stakeholders will not have enough time to make meaningful inputs into land use plans.

\subsection{Factors that Influence Community Participation in Plan Preparation}

Community participation in plan preparation depends on several factors and the study sought to identify these factors in the Tamale Metropolis. The factors that influence communities' ability to engage in participation in land use planning in order of priority are: resources, transparency, leadership quality, and centralisation of decision and the attitude of the people. Out of the 90 percent that agree that resources have a lot of influence on community participation, 68 percent strongly agree. This means that without resources, organising communities for a development decision will be difficult and for that matter a decision can be taken without inputs from the beneficiaries.

The Metropolitan Town Planning Director stated that inadequate resources affect most of the activities in the preparation of land use plans as a result technical people are not able to offer explanation to people on major proposed land uses and reasons certain activities should not be located in certain areas before a plan is completed. 
At the least prioritized among the factors is the attitude of the people that influences communities' participation. Out of about 80 percent disagree, 8.2 percent strongly disagree. This is quite strange because if meetings are scheduled and the people do not turn up, how could they participate?

It therefore means that to be able to promote participatory land use planning in the metropolis greater attention and consideration must be given to resources mobilization.

\subsection{Importance of Involving Communities in Preparation of Land Use Plans}

Community engagement is a condition for success as studies have demonstrated that involving citizens and partners in the work of community development raise more resources, achieve more holistic and ultimately more beneficial way. The study therefore considers how people view being part of the planning process in the communities.

From the field study it was realised that 54.5 percent and 50.9 percent of the respondents strongly agree that the essence of engaging the community in the planning process is to ensure efficiency of decisions and sustain the project respectively. By this, there is a clear indication that community members will feel like owners of a plan since they have been fully involved and will do everything possible to protect it as their property and anything. By this, people take decisions together and feel they are one and any decision taken will be in their interest. In addition, the decision-making process will be made efficient because it is going to minimise misunderstanding or possible disagreements and thus the resources in terms of the time and energy spent in explaining to people land use plan benefits, can be reduced.

Also, decisions taken can be based on the plan for efficiency, effectiveness and accountability. According to the Coordinator for Customary Land secretariat, "the local people will naturally feel happy that they are recognised by Planning Authorities in the decision-making process on their land and will definitely support the course very well". In order of priority of the importance of community engagement in the planning process is, the efficiency of decisions, sustainability of plan, effectiveness of decisions and self-reliance in the decision which is prioritized last by 18.2 percent of the respondents.

\subsection{Land Ownership system in the Metropolis}

There are two different types of land ownership in the Tamale Metropolis which are customary/traditional land ownership and state acquired lands. It was realised during the study that prospective developers acquire lands from sub-chiefs which are generally confirmed by the paramount chiefs before registration and development of the lands could be done.

The study revealed that on the preparation of land use plans, the customary land owners initiate the process in the Metropolis with the Assembly doing the approval. The chiefs and elders are usually the key stakeholders that are involved in plan preparation. This is done by giving inputs to the planners which might not necessary reflect the aspirations of the entire community.

The Gulkpegu Customary Land Secretariat admitted that it is important and necessary to involve community members in the process of plan preparation so that everybody will be aware of all the proposals especially the public uses and then take steps to protect them. The coordinator said over the years some community members become agitated when completed plans are being implemented on the ground and for that matter wider consultation of community members is laudable idea must be considered in the future plans.

\subsection{Main Challenges to Community Involvement in Preparation of Land Use Plans}

According to Bevir (2013), participation involves and concerns people, it is established in a social and cultural context given that participation is more than a physical input in development projects. From the discussion of participatory planning activities, it shows positive impact on sustainable land use planning and implementation; however, some challenges were identified from the study. From the field survey, 36.4 percent of the respondents identified inadequate resources as the most critical challenge to community involvement in plan preparation. This is supported by the MDPO and TPO as they strongly emphasized in their interviews that inadequate resources affect communities' participation.

Following the financial capacity issues is poor commitment of Metropolis as an issue of ineffectiveness of community involvement in the planning process. The Metropolis, which was of the view of 18.2 percent of the respondents hold the view that poor commitment of Metropolitan Planning Authority is a serious challenge to the organisation of participatory land use planning activities. It was further observed that 13.6 percent of the respondents saw poor communication and facilitation as a challenge while 10.9 percent noted that delay in decision making as a challenge. Though this challenge seems to be comparatively small, the significant role play by facilitation in participatory planning cannot be over looked and for that matter needs to be given attention.

\section{Findings, Recommendations and Conclusion}

This section of the paper summarises the finding of the study, suggested measures to be taken to address the 
critical issues raised and conclusion of the research.

\subsection{Findings}

The study looked at the involvement of communities in preparation and implementation of land use plans. With the knowledge of the decentralised planning system in the Tamale Metropolis, the study again showed that majority of the respondents have no knowledge or any form of idea about the decentralised planning system in the metropolis. Also, on the issue of involving the community members in the plan preparation process, the study revealed that community participation in land use plans preparation is generally low to an extent that most people in some communities are not even aware that their communities are covered by land use plans and major proposed areas for public uses. As to the main factors that influence community participation the preparation of land use plans, the study attributed it largely to resources, transparency and leadership qualities that are needed to engage the communities in the Metropolis.

The study further revealed that involving communities in the preparation of land use plans has a lot all of benefits to the general growth and development of communities. It was revealed that involving community members in the planning process will lead to sustainability, effectiveness, efficiency and self-reliance of the plans which will ensure enhances social cohesion and then protection of ecological sensitive areas in the community. The study also showed that the predominant techniques or tools used to organised communities during plan preparation are key stakeholders' meetings and workshops. According to the study, a particular technique can only be used once or not at all during the preparation of a given plan which is woefully inadequate to properly get the contribution of people into a completed plan.

On the issue of challenges to community participation, the study determined that there are a number of challenges that hampers the effective ways of organizing participation programmes. The critical challenges according to the study are poor commitment of the Metropolis planning authority and inadequate resources for spatial planning matters. Also the study revealed that low attention is given to spatial in the metropolis. Land Use Planning matters are mostly left in the hands of TCPD and the land owners/chiefs with the assembly doing the approvals of the plans as the planning Authority. This situation gives the chiefs the power to go into major proposed public land uses to the detriment of the future development needs of these communities.

A cursory look of the findings and the challenges indicate that engaging communities in the preparation of land use plans is very important. Since this gives the beneficiaries of these plans the opportunity to make meaningful inputs into the plans. This will eventually let the people feel ownership of the plans and for that matter appreciate all the proposals in the plan which will lead to affective implementation of the plans.

\subsection{Recommendations}

Community participating in the preparation of land use plans has the tendency to improve upon the implementation and execution of the plans. It is therefore significant that the community members who are the beneficiaries of the plans must be adequately involved in the process from the collection of both spatial and socio-economic data, design of alterative scenarios to the implementation of the plan on ground. Considering the findings from the study, the following are recommended in an attempt to address the findings.

There is need to sensitize the general public on the content of the decentralized planning system in Ghana. With the awareness of what is expected of community members in the planning process, it gives room for transparency and accountably which will promote affective implementation of completed land use plans. This will also let people know their roles in the planning process and are able to deliver when called upon.

Also, it is recommended that the Tamale Metropolitan assembly must ear mark or allocate a percentage of the revenue granted from spatial planning activities to TCPD purposely for organizing community workshops during plan preparation. Basically, with adequate resources, TCPD can be held accountable for not facilitating community participation activities in the metropolis during plan preparation.

In the process of preparing land use plans, draft copies must be displayed at public areas of communities with a technical officer around to explain the proposals within the plan to them. This situation will enable diverse groups of people who might not have the opportunity to participate in formal meetings to ask questions for clarification. This will allow for wider views of communities' members into the plan which will address the aspirations and actual needs of the people. Also, the data room concept proposed in the Land Use and Spatial Planning Authority Act, Act 925 of 2016 so data plans can be put there for the public to offer inputs. Again, intention to prepare land use plans must be published in the daily graphics for public comments into the process.

The study further recommends that participation in land use plan preparation should be extended to the implementation of the plan. This is because for land use plans implantation is where demarcation of various parcels of land is done on ground. This process will make it possible for communities to take cognisance of proposed public uses and then act as watchdogs to protect them for the interest of future development of communities.

Formation of community society groups as watchdogs who will take it upon themselves to ensure that 
communities participate adequately in the preparation of land use plans and their consequent implementation. These groups can hold the planning authorities accountable for not involving community members during the preparation and implementation of the plan.

Finally, community participation in preparation of land use plans must be tied to the Functional Organizational Assessment Tool (FOAT) such that the more a local authority engages its citizens in the plan preparation, the more funds that local authority will receive for its development activities.

\subsection{Conclusion}

The study focused mainly on the assessment of the involvement of community members of the Tamale Metropolis in the preparation and implementation of land use plans, though the decentralised planning system, which apparently has the tendency to improve upon the implementation and execution of the plans was weak and ineffective. This therefore translates into low awareness level of residents in the decentralised planning system within the Metropolis. Community participation in general is not a new phenomenon in Ghana, as policies and regulations have been put in place to empower and ensure that the local people participate in the decision making process.

As stated by Wasilwa (2015), participatory land use planning is people-centered bottom-up approach that recognises the differences that exist from place to place with respect to socio-economic, technological and environmental conditions. Looking at the direction land use planning is heading towards globally, Geographic Information System (GIS) cannot be ignored. However this study did not find out whether Participatory GIS was used in the preparation of land use plans in the metropolis. There is the need for further studies to consider Participatory Geographic Information System (GIS) in preparation of land use plans and their implementation. This is the new trend within the context of the urban environment, which this study was silent on even though the objectives of the study were achieved.

\section{REFERENCES}

Ahenkan, N. Bawole J., and Domfeh, K.A. (2013). Improving Citizens' Participation in Local Government Planning and Financial Management in Ghana: A Stakeholder Analysis of the Sefwi Wiawso Municipal Assembly.

Ainstein, S. (1969). 'A Ladder of Citizen Participation'. Journal of American Planning Association, 35(4), 216224

Aubel, G. R. and Samba, R. E. (2006). Study of Participatory Research in Health Promotion: Review and Recommendations for the Development of Participatory Research in Health Promotion in Canada. Ottawa, Canada: The Royal Society of Canada; 2006)

Babette, W. (2011). "Land Use Planning: Concepts, Tools and Applications". Published by Deutsche Gesellschaft fur, International Zusammenarbeit (GTZ) Gmbtt. Printed by Aksoyprint and project management.

Bastian, H and Bastian, F. A. (2006). People power: community participation in the planning of human settlements. Assignment children, (40), 11-47.

Bevir, T. R. (2013). Communities and their Development, An Introductory Study with Special Reference to the Tropics. London: Oxford University Press.

Eco-Trust, - Canada (2009). "BC First Nations Land Planning: Effective practices" -A Guide Prepared for the New Relationship Trust, University of Toroto press.

Fetterman D. M. (2005). Steps of empowerment evaluation: from California to Cape Town. Evaluation and Program Planning 2005;17(3), 305-313

Fortmann, L and Roe, R (2013): Political participation and three theories of democracy: A research inventory and agenda. European Journal of Political Research, 45(5), 787-810.

Freeman, M (2010). The importance of community participation in an ongoing Constructions of Primary Schools. A case study of Mlali and Mzumbe ward, University of Agder

Ghana Local Government Act, 1993 (Act 462), Printed by Ghana Publishing Corporation (Assembly press) Accra-Ghana

Ghana Local Governance Act, 2016 (Act 936), Printed by Ghana Publishing Corporation (Assembly press) Accra-Ghana

Goddard, G. and Cotter, S. (1987). Community Engagement in the Water Sector: An outcome-focused review of different engagement approaches. 1987, Cooperative Research Centre for Water Sensitive Cities: Melbourne

Kasiaka, K. (2004). "Participatory Planning and Sustainability of Water TASAF Water Project". UDSM Press, Tanzania.

Kumur, A. (2002): Monitoring and evaluating stakeholder's participation in agriculture and rural development project; Rome. FAO 
Mansuri, G. and Rao, B. (2004). Evaluating the efficacy of an empowerment-based self-management consultant intervention: results of a two-year randomized controlled trial. Therapeutic Patient Education 1(1), 3-11

Oakely, K. (2009). Approaches to participation in rural development. Geneva: ILO.

Schouten, E. R. and Moriarty, F. (2003): Stakeholders Engagement Achieving Sustainability in the construction sector, ISSN 2071-1050.

Shaeffer, G. (2008). Rural development: Putting the Last First. Essex, England, Longman Scientific and Technical publisher: New York.

Simpungwe, B (2006). Stories from rural hygiene promoters in Vanuatu: PHAST, tippy taps and working with men and women: community based approach, in Sharing experiences: Effective hygiene promotion in South-East Asia

Smith, H (2010). The Snakes and Ladders of User Involvement: Moving Beyond Arnstein. Health policy, 2010. 76 (2), 156-168.

The World Bank (2014), The principles of empowerment evaluation Empowerment Evaluation Principles in Practice 2014, 27-41

Thenen R. (2007). "Private Sector Participation in the Provision of Basic Infrastructure, African Trade Policy Center". Work in progress No. 6, Economic Commission for Africa

UNDP (2005). Celebrating Community Involvement: Leading lights, moving spirits and Lattice-work networks, Development Trusts Association visit www.dta.org.uk

Wasilwa, C. (2015). Effect of Community Participation on Sustainability of Community Based Development. Projects in Kenya. 2015, Bellac Research Consultants: Nairobi.

Woodhill, K. (2004). Stakeholder engagement: Good practical handbook for companies doing business in emerging market, International. 